\title{
URINE OUTPUT AND LACTATE IS NOT GOOD PARAMETERS FOR HEMODINAMIC ASSESSMENT IN VERY LOW BIRTH WEIGHT NEONATES
}

Oharomari Jr, L.K ${ }^{1 *}$; Sacramento, E.M.F. ${ }^{1}$; Martins-Celini, F.P. ${ }^{1}$; de Melo, N.B. ${ }^{1}$; Aragon, D.C. ${ }^{1}$; Rinaldi, D.T.N. ${ }^{1}$; Dutra, L.F.1; Okumura, M.C. ${ }^{1}$; Vieira, M.F. ${ }^{1}$; Calixto, C. ${ }^{1}$; Gonçalves-Ferri, W.A. ${ }^{1}$ ${ }^{1}$ Department of Pediatrics, Ribeirão Preto School of Medicine, University of São Paulo, Brazil

\section{Background}

- The assessment of hemodynamic status of the preterm neonates remains a challenge. Although blood pressure is still used as a parameter of the circulatory failure, either an appropriate threshold value nor better outcomes after treating hypotension were found.

- Several methods of diagnostic measures have been investigated, such as functional echocardiography, serum lactate, base excess, capillary refill time and superior cava vein flow.

\section{Objective}

- To analyse the specificity and sensibility of lactate and urine output together to adverse outcomes and use of inotrope.

\section{Methods}

- Retrospective study.

- Included: preterm infants $<1500$ g born in 2016 and 2017 and did not died at delivery room nor had malformations.

- Excluded: missing data.

- Determined through a ROC curve the sensitivity and specificity of lactate and urine output in $1^{\text {st }} 24$ and 48 hours the newborns that developed adverse outcomes (death within the first 10 days, pulmonary hemorrhage) and that used inotropes.

- Logistic regression model to obtain a linear equation associating diuresis and lactate for the first 24 and 48 hours of life with adverse outcomes obtaining values of a composite variable for each individual and using this new parameter ( $\mathrm{R}$ software version 3.4.2).

\section{Results}

-Included: 233 newborns.

-Mean of gestational age and birth weight: 198,2 weeks and 947,6 grams.

- No value with good specificity and sensitivity for death within the first 10 days of life, pulmonary hemorrhage and use of inotropes were found.

- All the areas under the curve were below 0,7 .
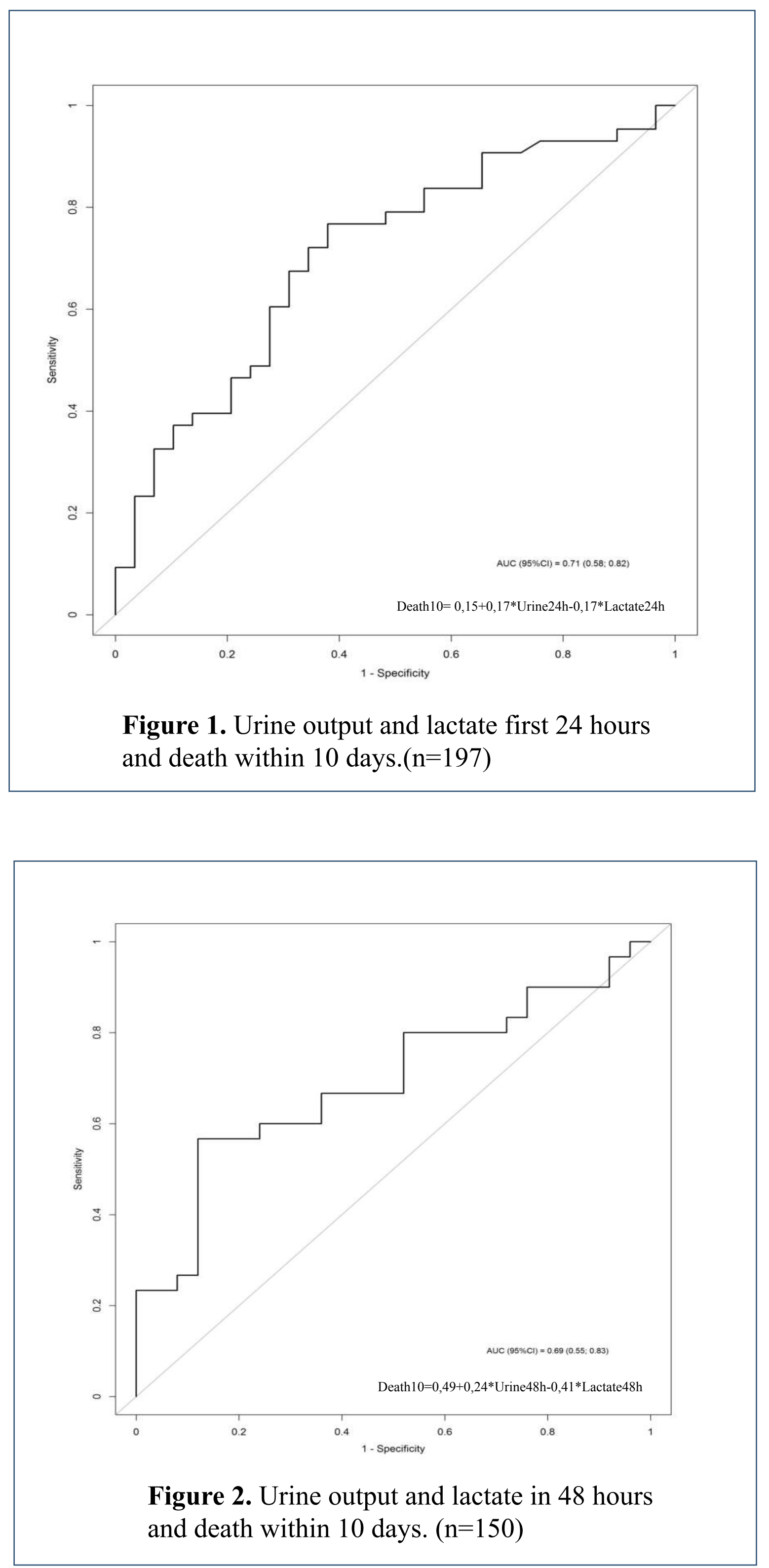

\section{Conclusion}

- No single clinical or biochemical parameter was found to be a good marker for preterm shock.

- The subjective clinical and biochemical evaluation together continue to be standard to determinate the use of inotropes 